\title{
Female Adolescents And Reproductive Change In Ghana: Evidence From An Adolescent Survey Of Two Communities
}

\author{
Stephen O. Kwankye \\ Regional Institute of Population Studies \\ Legon, Ghana
}

\begin{abstract}
The study on Female Adolescent Reproductive Change was undertaken as part of the ongoing effort at understanding some of the problems that confront adolescents in Ghana. The study uses a sample of 1,828 female adolescents aged 12-24 years (1,503 from Cape Coast and 325 from Mankrong) in the Central Region of Ghana as a case study. This has the primary purpose of comparing the situation in an urban vis-à-vis a rural area. The general objective of the study is to examine the possible changes in the reproduction among female adolescents within the context of overall fertility decline in Ghana as a way of assessing the progress made in addressing adolescent reproductive health problems following the adoption of a national adolescent reproductive health policy in Ghana. The study examines age at first sex, first marriage, first pregnancy and first birth as a way of finding out any changes that might have occurred in the recent past. It also looks at issues pertaining to pregnancy incidence and wastage as may be related to school attendance. Throughout, comparisons are made with reports from the Ghana Demographic and Health Surveys (GDHS) and other small-scale studies that have been done in certain areas in Ghana. Overall, the study finds that major positive changes have occurred among female adolescents first with respect to the proportion of female adolescents ever having sexual activity. More and more female adolescents continue to abstain from sex. However, among the small proportion that ever indulges in sex, sexual initiation appears to be earlier when age is controlled for.
\end{abstract}

\section{Introduction}

Adolescent sexuality and reproduction are issues that have attracted worldwide recognition as social problems of development. In Ghana, the evidence suggests declines in overall fertility in the recent past. For example, between 1988 and 1993, overall fertility in Ghana is reported to have declined by almost one child per woman from 6.4 to 5.5 (Ghana Statistical Service (GSS) and Macro International Inc. (MII), 1994). There has also been a further decline to 4.6 in 1998 and to 4.4 in 2003 (GSS and MII, 1994 and 2004). In most developing countries, it appears that reduction in fertility among younger women would be achieved mainly through the postponement of marriage. However, with age at marriage in Ghana steadily rising, the risk of out-ofwedlock pregnancy among individual adolescent women is likely to increase as pre-marital sex continues with little or no contraceptive use. 
Rapid urbanization in Ghana has been the result of natural population increase as well as inter- and intra-regional movements, which in recent times, appear to be dominated by adolescents and the youth in search of jobs particularly in the cities and large towns. Separation of these young persons from their parents obviously is likely to result in the steady breakdown of traditional, parental and social controls on the lifestyles of the young migrants. Because of difficulty in getting jobs in their places of destination, many female adolescents may be tempted to take to risky sexual behaviours as a matter of survival and, in the process may begin childbearing earlier than anticipated. Another aspect of risk that young females go through is defilement which appears to be increasing and has attracted much concern. Apart from its criminal nature, adolescent female defilement or rape carries with it long term reproductive, psychological and health implications for the female adolescent victim of sexual abuse.

The issues of adolescent sexual activity and reproduction are likely to become increasingly more important in Africa in the near future due to urbanization and the dramatic growth in secondary schooling (Cherlin and Riley, 1986). Adolescent sexuality in Ghana is of concern because some sections of the adult population particularly some religious groups in the country do not endorse contraceptive use among sexually active adolescents.

This paper is an extraction from a comprehensive research carried out to find out the ramifications of female adolescent sexuality, contraceptive use and reproductive health in Cape Coast, the regional capital of Central Region of Ghana and Mankrong, a rural settlement located in the interior of the region. The results of the analysis are from an Adolescent Survey of Cape Coast and Mankrong during August-September, 1997.

\section{The Problem}

Ghana is among countries of sub-Saharan Africa which has been experiencing rapid population growth. In recent times, the population problem has been assuming different dimensions including adolescent fertility, which is the result of early age at sexual experience (usually out of wedlock) with little or no contraception. As a result, teenage pregnancies and their accompanying child delinquency and poor development of the female adolescent victim are unfolding problems that Ghana will have to contend with.

There is the socio-cultural environment within which adolescent sexuality takes place. In Ghana, it is felt in many circles that it is culturally unwelcome to discuss sexual issues with the adolescent. In fact, many 
parents are handicapped in discussing sexual and reproductive health matters with their children. Even some family planning service providers frown upon the provision of family planning services to these youngsters. In 1994, the GSS reported that $40 \%$ of service providers expressed their unwillingness to provide family planning services such as intra-uterine device (IUD) and injectables to unmarried adolescents and $25 \%$ of them would not administer the pill under the same conditions (GSS, 1994). Thus, although it is clear that adolescent sexuality is a common phenomenon of Ghana's social life, adolescents are not encouraged to access family planning methods to avoid any untimely pregnancies should they choose to have sex. Some girls therefore continue to have their future development permanently impaired through early practice of sex and subsequent unplanned pregnancies.

Data are not readily available on abortion in Ghana, but in a society where adolescents are increasingly indulging in sex with little or no contraception, it is obvious that abortion will be resorted to by some of the girls who become pregnant. Increasing unsafe abortion could therefore contribute to high maternal mortality ratios in Ghana. Data from the National AIDS Control Programme suggest that a higher proportion of AIDS infection takes place during adolescent ages of 15-19 years. This is because the 30-34 year group so far has reported the highest number of AIDS cases with 18.8\% (Ghana AIDS Commission, 2004). It can be deduced that considering that the incubation period of AIDS ranges between 5 and 12 years or more, it is possible that many of the reported AIDS cases in the age groups spanning 20-39 are likely to have been contracted within adolescent ages.

In the 1998 GDHS, it was found that $13.8 \%$ and $40.1 \%$ of women aged $15-19$ and 20-24 years respectively were sexually active in the last four weeks preceding the survey. However, overall, $37.8 \%$ and $91.4 \%$ had ever had a sexual activity respectively among women of $15-19$ and 20-24 years. In 2003, $39 \%$ and $84.3 \%$ of women $15-19$ and $20-24$ years respectively, had ever had a sexual activity in Ghana. Meanwhile, only $6.5 \%$ of women in 1998 and 7.3\% in 2003 aged $15-19$ years and $42.4 \%$ of women in 1998 and $40.2 \%$ in 2003 aged 20-24 years were enumerated as married. This suggests a relatively high sexual activity among young women including the never married in Ghana.

Linked to the high sexual activity among young women is their low contraceptive use. For example, current contraceptive use for modern methods in 1993 was $5.0 \%$ and 8.3\% among women of 15-19 and 20-24 years respectively compared to $9.3 \%$ among all women in Ghana (GSS and MII, 1994). The corresponding figures for 1998 were $4.8 \%$ and $10.4 \%$ among women of 15-19 and 20-24 years respectively compared to $10.7 \%$ among all 
women in Ghana. The implication is that low contraceptive use among adolescent and young women may foreclose education and employment opportunities to many of them as they expose themselves to risks of unplanned pregnancies. The key question this paper seeks to answer therefore is what possible changes have occurred in the reproductive behaviour of female adolescents with respect to their age at first sexual activity, first pregnancy, first birth and pregnancy wastage?

\section{Rationale of the Study}

The study is considered both important and timely for a number of reasons. First, it is acknowledged that adolescent reproductive health issues have become problems of national interest and concern. In line with this reasoning, the National Population Policy (Revised Edition) of Ghana (Government of Ghana, 1994), unlike the 1969 Ghana Population Policy, highlights adolescent reproductive health as one key area that requires critical attention in the nation's population programmes. The Revised Population Policy therefore calls for increased efforts at empowering women through increasing female education. A research of this nature is thus relevant in bringing to the fore the various dimensions of adolescent sexual and reproductive health problems to attract increased government attention and funding.

Adolescent childbearing rates in Ghana have been found to be highest in the Central Region in both 1993 and 2003 (GSS and MII, 1994 and 2004). In 1993, $33.3 \%$ of female adolescents aged 15-19 years in the Central Region had begun childbearing compared to $21.6 \%$ for the entire country. In the 1998 GDHS however, the region recorded a relatively lower percentage of adolescents having begun childbearing (18.7\%) to place third after Eastern Region (21.2\%) and Ashanti (19.6\%) compared to a national average of $14.1 \%$. Yet, in 2003, the region recorded the highest percentage of adolescents (24.1\%) having begun childbearing compared to a national average of $13.8 \%$ (GSS and MII, 2004).

Since AIDS and sexually transmitted infections (STIs) appear to be occurring mostly among adolescents, it is relevant to examine reproductive changes among young persons as a way of offering concrete recommendations for the implementation of family planning programmes with special reference to adolescents who are at a relatively higher risk to HIV/ AIDS in Ghana. It is also important to indicate that the 1993, 1998 and 2003 GDHS covered only adolescents of 15-19 years and not those below 15 years, a research gap which, this paper attempts to fill. 
The study is however, limited by its concentration on female adolescents as against males as well as its over-sample of adolescents in Cape Coast relative to Mankrong. However, it has to be acknowledged that in situations where a male adolescent impregnates a female adolescent, it is the female that usually drops out of school. Any complications that occur during childbearing also affect women and not men. Biologically too, reproductive health problems are more grave when women are involved compared to men. The bias of the study towards women though a limitation, is also justified within the context of on-going efforts at improving the socioeconomic plight of women especially adolescents in Ghana.

The general objective of the study is to examine the possible changes in the reproduction among female adolescents within the context of overall fertility decline in Ghana. Specifically, the study seeks to estimate the age at first sexual activity among female adolescents in the study areas to see the changes that have taken place. It also examines the changes in age at first pregnancy and pregnancy wastage, discusses the variation of childbearing among the female adolescents in respect of differences in their socioeconomic characteristics and makes recommendations to guide policies towards addressing sexuality and adolescent reproductive health problems in Ghana. The study examines the hypothesis that there is a direct relationship between contraceptive use at first sex and age at first sexual activity among female adolescents.

\section{Sources of Data and Methodology}

The main source of data for the study is from a survey undertaken in Cape Coast and Mankrong in the Central Region of Ghana in August-September 1997. The two study areas were chosen purposely for comparing reproductive changes in an urban vis-à-vis a rural area. Respondents were females aged 1224 years in the two study areas. Secondary sources including the Ghana Demographic and Health Surveys as well as information gathered from focus group discussions were also used.

The selection of the sample for the study in Cape Coast was carried out in two stages. First, Cape Coast was divided into 34 clusters made up of 15 lowincome, 11 middle-income and 8 high-income residential areas to form the sampling units. These were the Town and Country Planning Department (TCPD) demarcated clusters in the town. Simple random sampling was used to select the clusters for the study, taking into account their spatial location such that clusters that were eventually selected cut across the Cape Coast Township and all socio-economic groups. With this at the background, three clusters were each selected from the high and middle-income residential areas and four from the low-income residential areas. In all, 10 residential clusters were selected for enumeration in Cape Coast. 
At the second stage, the survey selected a total sample of 1,503 female adolescents aged 12-24 years (approximately 150 from each of the 10 residential clusters in Cape Coast). The survey was therefore targeted purposively at households that had females of 12-24 years who were subsequently selected for interview with the individual questionnaire. On the contrary, considering the small size of Mankrong (made up of Mankrong and Mankrong Junction) a total enumeration of all households was undertaken and females aged 12-24 years selected for the individual questionnaire. Overall, the survey achieved a sample of 1,828 female adolescents (i.e., 1,503 in Cape Coast and 325 at Mankrong) of 12-24 years.

Two sets of questionnaire were administered: a household questionnaire and an individual questionnaire for eligible females aged 12-24 years. Collecting information from females aged 12-24 years facilitated a comparison between females aged 15-19 years and 20-24 years as well as adolescents below 15 years of age. Apart from the structured questionnaire, the study conducted focus group discussions among some selected male and female adolescents on one hand, and some male and female adults on the other in respect of their views on sexuality and the reproductive health of female adolescents pertaining to each of the study areas. These sources of data enabled the study answer some fundamental sociological questions about adolescent reproduction in these study areas. The qualitative data collected from the focus group discussions provided additional information to strengthen the results of the quantitative analysis. Simple techniques of analysis, including cross tabulations, rates, ratios and proportions have been employed beside the use of multiple regression analysis.

\section{RESULTS Age at First Sex}

The survey asked the adolescents whether or not they had ever had a sexual intercourse. Table 1 shows that overall, a little over a third of the female adolescents had ever had sex at the time of the survey. The percentage of adolescents who have ever had sex also increases with age. There is, however, a relatively higher percentage of adolescents who had ever had sex in Mankrong than in Cape Coast, except at ages less than 15 years where the result is to the contrary. 
Table 1. Percent Distribution of Adolescents Who Have Ever Had Sex by Current Age, Cape Coast and Mankrong

\begin{tabular}{|c|c|c|c|c|c|c|c|c|c|}
\hline $\begin{array}{c}\text { Current } \\
\text { Age }\end{array}$ & \multicolumn{3}{|c|}{ Cape Coast } & \multicolumn{3}{c|}{ Mankrong } & \multicolumn{3}{c|}{ Total } \\
\cline { 2 - 9 } & All & $\begin{array}{c}\text { Ever } \\
\text { had } \\
\text { sex }\end{array}$ & $\% *$ & All & $\begin{array}{c}\text { Ever } \\
\text { had } \\
\text { sex }\end{array}$ & \%* & All & $\begin{array}{c}\text { Ever } \\
\text { had sex }\end{array}$ & $\%^{*}$ \\
\hline$<15$ & 389 & 6 & 6.0 & 100 & 0 & 0.0 & 489 & 6 & 1.2 \\
$15-19$ & 687 & 203 & 29.5 & 110 & 44 & 40.0 & 797 & 247 & 31.0 \\
$20-24$ & 427 & 327 & 76.6 & 115 & 99 & 86.1 & 542 & 426 & 78.6 \\
Total & 1,503 & 536 & 35.7 & 325 & 143 & 44.0 & 1,828 & 679 & 37.1 \\
\hline
\end{tabular}

It is to be noted that the 1993 GDHS recorded that by the age of 15 , only $12 \%$ of the respondents had ever had sexual relations. However, by age 20, more than $85 \%$ of women had had sexual intercourse at the time of the survey for the whole of Ghana. The corresponding figure for women aged 20-24 years in the 1998 GDHS was $81.4 \%$. The 1998 and 2003 GDHS also respectively found that $62 \%$ and $61 \%$ of women of $15-19$ years had never had sex. This finding compares with that of the current study where $69 \%$ of women of age 15-19 years (not shown in table) had never had sex at the time of the survey. The proportion that had ever had sexual intercourse in Mankrong was however, higher than Cape Coast by almost $10 \%$.

The timing of first sexual activity among the adolescents presented in Figure 1 indicates that the peak period of first sexual activity is within 15-19 years where as high as $82 \%$ of the respondents indicated having had sexual intercourse for the first time. It is however, higher in Mankrong (91\%) compared to Cape Coast $(80.0 \%)$. Conversely, a relatively higher proportion of the adolescents in Cape Coast had their first sexual experience earlier (i.e. less than 15 years) than their counterparts in Mankrong: almost 10\% had sexual intercourse at ages less than 15 years in Cape Coast compared to $4 \%$ in Mankrong. There is also a higher proportion of respondents in Cape Coast initiating sexual intercourse at ages between 20 and 24 years $(10 \%)$ than in Mankrong (a little less than 5\%). This suggests that although a relatively higher proportion of adolescents start sexual intercourse earlier in Cape Coast than at Mankrong, at later ages (20-24 years) one is likely to find a relatively higher proportion of them yet to be initiated into sex in Cape Coast compared to their counterparts in Mankrong. 
Figure 1. Percentage Distribution of Female Adolescents Ever Having Sex by Age at First Sex, Cape Coast and Mankrong

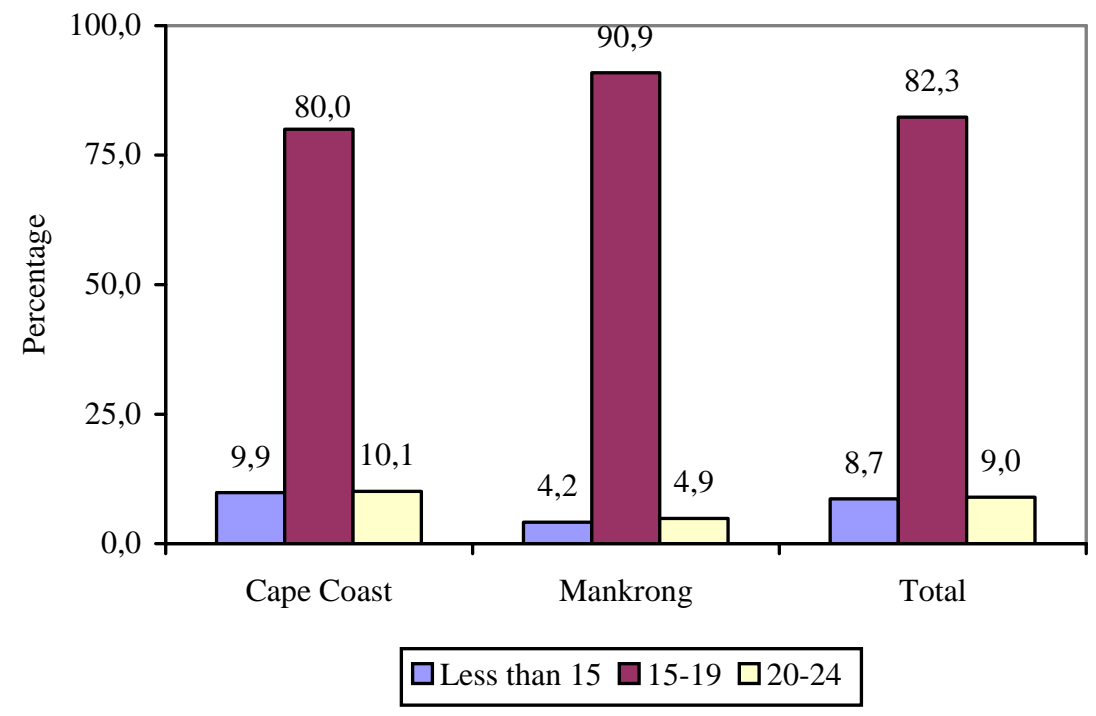

The mean age at first sexual intercourse is about the same in the two study areas, 16.9 years in Cape Coast and 17.0 years in Mankrong. This finding is quite inconsistent with the expected situation of a much lower mean age at first sexual intercourse in a rural than the urban area in Ghana. It is however, to be noted that a relatively higher proportion of the respondents were sexually active by age 19 years in Mankrong (rural area) compared to Cape Coast (urban area). The pattern of distribution of mean age at first sex (Table 2) suggests a possible decline in the age at first sexual intercourse for respondents in both study areas. This is because as current age increases, mean age at first sex also generally increases. None of the adolescents aged 12-14 years in Mankrong responded to have ever had sexual intercourse. In spite of this, it was found that mean age at first sex for respondents aged 15-19 years was 16.1 as against 17.4 for those aged 20-24 in Mankrong. Similarly, it was 12.8, 15.9 and 17.5 respectively for adolescents aged 12-14, 15-19 and 20-24 years in Cape Coast. It has to be clarified, however, that while the proportion of persons becoming sexually active by the age of 20 years appears to be reducing compared to the 1993, 1998 and 2003 GDHS results, the incidence of first sexual intercourse among those who had ever had a sexual experience seems to occur earlier in age than was recorded in the GDHS reports (GSS and MII, 1994, 1999 and 2004). 
Table 2. Mean Age at First Sex of Adolescents by Current Age, Cape Coast and Mankrong

\begin{tabular}{|c|c|c|}
\hline Current Age & $\begin{array}{c}\text { Mean age at first sex } \\
- \\
\text { Cape Coast }\end{array}$ & $\begin{array}{c}\text { Mean age at first sex - } \\
\text { Mankrong }\end{array}$ \\
\hline$<15$ & 12.8 & - \\
$15-19$ & 15.9 & 16.1 \\
$20-24$ & 17.5 & 17.4 \\
Total & 16.9 & 17.0 \\
\hline
\end{tabular}

\section{Age at First Marriage}

From the data only a small proportion (5.3\% in Cape Coast and $20.0 \%$ in Mankrong) of the adolescents had ever been married. A higher proportion of the few who had ever been married were also between 20 and 24 years. The results showed that in both study areas, mean age at first marriage increases with age. The variation in age at first marriage by persons who influenced the decision of the female adolescents to marry was analyzed.

A comparison of the respondents in the two study areas further shows that those in Mankrong had a relatively lower overall mean age at marriage than their counterparts in Cape Coast although the difference between them is quite negligible (Table 3). This is to be expected in view of Mankrong's status as a rural area, the residents of which are more likely to marry earlier than their colleagues who are domiciled in urban areas such as Cape Coast.

Table 3. Mean Age at First Marriage by Current Age of Female Adolescents,

\section{Cape Coast and Mankrong}

\begin{tabular}{|c|c|c|c|}
\hline \multirow{2}{*}{$\begin{array}{l}\text { Current } \\
\text { Age }\end{array}$} & \multicolumn{3}{|c|}{ Mean age at first marriage } \\
\cline { 2 - 4 } & Cape Coast & Mankrong & Both \\
\hline 17 & $17.0^{*}$ & - & $17^{*}$ \\
18 & $18.0^{*}$ & $15.0^{*}$ & 16.5 \\
19 & 17.9 & 18.1 & 18.0 \\
20 & 18.6 & 18.4 & 18.5 \\
21 & 19.6 & 18.6 & 19.0 \\
22 & 19.7 & 19.4 & 19.7 \\
23 & 19.3 & 21.2 & 20.5 \\
24 & 20.9 & 21.3 & 21.0 \\
Total & 19.7 & 19.4 & 19.5 \\
& & & \\
& & & \\
& & & \\
\end{tabular}

Note: *Only one person is involved 
A comparison of the two study areas further, indicated that apart from the situation where the decision to marry was said to have been influenced by both parents, mean age at first marriage was lower in Mankrong than in Cape Coast irrespective of the person supposed to have influenced the adolescent to marry. It is also striking to observe that in either Cape Coast or Mankrong, female adolescents who said their decision to marry at the time they did was influenced by their friends portray a higher tendency to marry earlier than their counterparts who cited persons other than their friends to have influenced their decision to marry (Table 4). It was also found that mean age at marriage is highest among women whose first marriages were said to have been influenced by other relations of theirs in Cape Coast. On the other hand, among adolescents in Mankrong, the highest mean age at marriage was recorded in respect of marriages said to have been influenced by their own partners.

Table 4. Mean Age at First Marriage of Female Adolescents by Person Influencing Her to Marry

\begin{tabular}{|l|c|c|}
\hline \multirow{2}{*}{ Person influencing the marriage } & \multicolumn{2}{|c|}{ Mean age at Marriage } \\
\cline { 2 - 3 } & Cape Coast & Mankrong \\
\hline Both parents & 19.3 & 19.6 \\
Mother only & 19.0 & - \\
Father only & 20.0 & 19.0 \\
Other relations & 20.5 & 19.0 \\
Partner & 20.1 & 19.8 \\
Friends & 18.0 & 17.5 \\
Self & 19.6 & 19.5 \\
Total & 19.7 & 19.4 \\
& & \\
& & \\
\hline
\end{tabular}

\section{Age at First Pregnancy}

The study examined the age at first pregnancy and the number of times an adolescent has become pregnant. In Table 5 a small proportion of the adolescents reportedly had ever become pregnant at the time of the survey, i.e., $11.7 \%$ in Cape Coast and $25.5 \%$ in Mankrong. Overall, it appears that approximately two in three of the respondents who had ever had a pregnancy reported to have had only one pregnancy in either Cape Coast or Mankrong although the proportion is slightly higher in Mankrong. Higher pregnancy rates have, however, been recorded in a study by Agyei and Epema (1990) in Kampala, Uganda where, by age 17 years, $30 \%$ of the women had one or more pregnancies with one in six of them found to be currently pregnant in addition to an average of 2.15 pregnancies among all adolescents. It is also important to note that in either study area, many of the adolescents who reported to have had up to three or more pregnancies, were relatively older, i.e., more than 19 years and hence were exposed to relatively lesser reproductive health risks. 
It is also observed that among either adolescents less than 20 years or within 20-24 years, a high proportion of them had had one pregnancy only. This is especially the case among adolescents less than 20 years (79\% in Cape Coast and $92 \%$ in Mankrong). In the case of the youth of 20-24 years, the proportion having one pregnancy only reduces in either study area while that for second and third pregnancies increases in comparison with their counterparts less than 20 years. This is expected since at these ages, many of them may be married and hence it may not be uncommon for many of them to have more than one pregnancy. For example, while $16.4 \%$ of women $20-24$ years in Cape Coast were ever married, close to half (47.4\%) of their counterparts in Mankrong were ever married. Accordingly, the proportion of adolescents that have ever been pregnant within age 20-24 years in Mankrong is higher (84.3\%) than the case is in Cape Coast $(75.6 \%)$. This suggests that the observed higher proportion of adolescents ever becoming pregnant in Mankrong is largely among the youth aged 20-24 years. From Table 5, while about one in four of the adolescents ever becoming pregnant in Cape Coast, was aged less than 20 years, the corresponding figure for Mankrong was one in six adolescents.

Table 5. Percent of Female Adolescents by Current Age and Number of Times

Pregnant, Cape Coast and Mankrong

\begin{tabular}{|c|c|c|c|c|c|c|c|c|c|c|}
\hline \multirow[b]{4}{*}{ Age } & \multicolumn{10}{|c|}{ Number of Times Pregnant } \\
\hline & \multicolumn{5}{|c|}{ Cape Coast } & \multicolumn{5}{|c|}{ Mankrong } \\
\hline & \multirow[t]{2}{*}{1} & \multirow[t]{2}{*}{2} & \multirow[t]{2}{*}{$3+$} & \multicolumn{2}{|c|}{ Total } & \multirow[t]{2}{*}{1} & \multirow[t]{2}{*}{2} & \multirow[t]{2}{*}{$3+$} & \multicolumn{2}{|c|}{ Total } \\
\hline & & & & $\mathbf{N}$ & $\%$ & & & & $\mathbf{N}$ & $\%$ \\
\hline $15-19$ & 79.1 & 16.3 & 4.6 & 43 & 24.4 & 92.3 & 7.7 & 0.0 & 13 & 15.7 \\
\hline $20-24$ & 53.4 & 32.3 & 14.3 & 133 & 75.6 & 62.9 & 24.3 & 12.8 & 70 & 84.3 \\
\hline Total\% & 60.6 & 27.4 & 12.0 & - & 100.0 & 67.5 & 21.7 & 10.8 & - & 100. \\
\hline $\mathrm{N}$ & 105 & 50 & 21 & 176 & - & 56 & 18 & 9 & 83 & 0 \\
\hline
\end{tabular}

Note: ${ }^{*} 11.7 \%$ had ever become pregnant in Cape Coast compared to $25.5 \%$ in Mankrong.

Comparing the adolescents based on their marital status vis-à-vis the number of times they have been pregnant, it was observed that in either Cape Coast or Mankrong, a relatively higher proportion of the ever married adolescents have had more pregnancies compared to the never married among whom a large proportion have had one pregnancy only (Table 6). However, it is equally worrying to note that among the never married adolescents, there are some who have had three pregnancies or more. 
Table 6. Percentage of Female Adolescents by Age Group, Marital Status and Number of Times Pregnant, Cape Coast and Mankrong

\begin{tabular}{|c|c|c|c|c|c|c|c|c|c|c|}
\hline \multirow{4}{*}{$\begin{array}{l}\text { Marital } \\
\text { Status }\end{array}$} & \multicolumn{10}{|c|}{ Age and Number of times pregnant } \\
\hline & \multicolumn{5}{|c|}{ Less than 20 years } & \multicolumn{5}{|c|}{$20-24$ years } \\
\hline & \multirow[t]{2}{*}{1} & \multirow[t]{2}{*}{2} & \multirow[t]{2}{*}{$3+$} & \multicolumn{2}{|c|}{ Total } & \multirow[t]{2}{*}{1} & \multirow[t]{2}{*}{2} & \multirow[t]{2}{*}{$3+$} & \multicolumn{2}{|c|}{ Total } \\
\hline & & & & $\mathbf{N}$ & $\%$ & & & & $\mathbf{N}$ & $\%$ \\
\hline \multicolumn{11}{|l|}{$\begin{array}{l}\text { Cape } \\
\text { Coast }\end{array}$} \\
\hline Never & 75.8 & 21.2 & 3.0 & 33 & 100.0 & 57.7 & 31.0 & 12.3 & 71 & 100.0 \\
\hline Married & 90.0 & 0.0 & 10.0 & 10 & 100.0 & 48.4 & 33.9 & 17.7 & 62 & 100.0 \\
\hline $\begin{array}{l}\text { Ever } \\
\text { Married } \\
\text { Total }\end{array}$ & 79.1 & 16.3 & 4.6 & 43 & 100.0 & 53.4 & 32.3 & 14.3 & $\begin{array}{l}13 \\
3\end{array}$ & 100.0 \\
\hline \multicolumn{11}{|l|}{$\begin{array}{l}\text { Mankro } \\
\text { ng }\end{array}$} \\
\hline Never & 100.0 & 0.0 & 0.0 & 4 & 100.0 & 80.0 & 20.0 & 0.0 & 20 & 100.0 \\
\hline Married & 88.9 & 11.1 & 0.0 & 9 & 100.0 & 56.0 & 26.0 & 18.0 & 50 & 100.0 \\
\hline $\begin{array}{l}\text { Ever } \\
\text { Married } \\
\text { Total }\end{array}$ & 92.3 & 7.7 & 0.0 & 13 & 100.0 & 62.9 & 24.3 & 12.8 & 70 & 100.0 \\
\hline
\end{tabular}

The analysis of the mean age at first pregnancy among the adolescents (Table 7) also showed a relatively lower age in Cape Coast (18.6 years) compared to Mankrong (18.8 years). What this means is that although in the towns, more adolescents do not get pregnant relative to the rural areas, yet pregnancies when they occur could be relatively earlier in the towns compared to the villages. This is however, contrary to expectation and could be the result of possible age misreporting among the adolescents in Mankrong in respect of age at first pregnancy. In 1996, Nabila and Fayorsey found that adolescent pregnancies and impregnation among a sample of adolescents in Accra and Kumasi begin as early as age 13 but the mean age at first pregnancy was found to be 17 years which is a little over a year lower than the current finding from Cape Coast and Mankrong. This obviously suggests a little bit of an improvement with time. 
Table 7. Mean Age at First Pregnancy of Female Adolescents by Number of Times Pregnant, Cape Coast and Mankrong

\begin{tabular}{|c|c|c|c|c|}
\hline $\begin{array}{c}\text { Number of times } \\
\text { pregnant }\end{array}$ & \multicolumn{2}{|c|}{ Cape Coast } & \multicolumn{2}{|c|}{ Mankrong } \\
\cline { 2 - 5 } & $\mathbf{N}$ & Mean (years) & $\mathbf{N}$ & Mean (years) \\
\hline 1 & 105 & 19.2 & 56 & 19.0 \\
2 & 49 & 18.0 & 18 & 18.4 \\
$3+$ & 21 & 17.3 & 9 & 18.7 \\
Total & 175 & 18.6 & 83 & 18.8 \\
& & & & \\
\hline
\end{tabular}

Note: One person from Cape Coast having had two pregnancies did not state her age at first pregnancy and hence was not included in the table.

The study again examined the relationship between education and pregnancy incidence (Table 8). Using current education of the adolescent, it was found that the minimum mean age at first pregnancy among the adolescents occurred after the age of 17 years (i.e., 17.3 years) at which time, those who might have gone to school would, all things being equal, have completed at least Junior Secondary School and even could be in the Senior Secondary School. To some extent therefore, the data presented here could shed some light on the role of education in the incidence of pregnancies among adolescent females.

It was again observed that some form of education is important in reducing the repeated incidence of pregnancies during the period of adolescence. The evidence is that with the exception of educational categories with few cases, adolescents with no education tend to have higher number of pregnancies compared to their counterparts with any level of formal education. For example, while almost 32\% (Cape Coast) and 25\% (Mankrong) of the adolescents with no education have had up to three or more pregnancies, the proportion pertaining to other educational categories is less than $10.0 \%$. This observation is reinforced by the fact that the proportion of adolescents who have only one pregnancy is lowest among adolescents who have no education compared to their counterparts of other levels of education. The implication of this, is that among adolescents with no education, relatively higher proportions have had two or more pregnancies than adolescents of other higher educational levels. In this regard retention of young adolescents in school could reduce incidence of both first and repeated pregnancies. 
Table 8. Percent of Female Adolescents by Number of Times Pregnant and Level of Education, Cape Coast and Mankrong

\begin{tabular}{|l|c|c|c|c|c|c|c|c|}
\hline \multirow{2}{*}{ Education } & \multicolumn{8}{|c|}{ Number of pregnancies } \\
\cline { 2 - 9 } & \multicolumn{7}{|c|}{ Cape Coast } & \multicolumn{5}{c|}{ Mankrong } \\
\cline { 2 - 9 } & $\mathbf{1}$ & $\mathbf{2}$ & $\mathbf{3 +}$ & Total & $\mathbf{1}$ & $\mathbf{2}$ & $\mathbf{3 +}$ & Total \\
\hline No education & 36.8 & 31.6 & 31.6 & 100.0 & 58.3 & 16.7 & 25.0 & 100.0 \\
Primary & 60.6 & 30.3 & 9.1 & 100.0 & 66.7 & 23.8 & 9.5 & 100.0 \\
Arabic* & 66.7 & 33.3 & - & 100.0 & - & - & - & 100.0 \\
Middle/JSS & 63.4 & 26.9 & 9.7 & 100.0 & 71.4 & 25.7 & 2.9 & 100.0 \\
SSS/Secondary & 61.5 & 30.8 & 7.7 & 100.0 & 100.0 & - & - & 100.0 \\
Post- & & & & & & & & \\
Secondary/High & 50.0 & - & 50.0 & 100.0 & - & - & - & - \\
er* & 105 & 50 & 21 & 176 & 56 & 18 & 9 & 83 \\
Total Number & & & & & & & & \\
\hline
\end{tabular}

Note:* Less than 5 cases involved.

The study also examined the pregnancy situation among the adolescents during the last 12 months before the survey. The results presented in Figure 2 indicate that only about $5.5 \%$ of the adolescents in Cape Coast reported to have been pregnant in the last 12 months compared to $15.1 \%$ among their counterparts in Mankrong. Overall, however, 27.3\% of the pregnancies occurred to adolescents below 20 years. The breakdown by study area also showed that the proportion of the pregnancies occurring to adolescents less than 20 years was higher in Cape Coast $(32.5 \%)$ compared to Mankrong $(18.3 \%)$. This is an indication that although overall pregnancies are lower in Cape Coast, the proportion of pregnancies to persons less than 20 years (where reproductive health risks are much higher), is higher in Cape Coast, compared to Mankrong. 
Figure 2. Percent of Female Adolescentsand the Youth Ever Becoming Pregnant in the Past Twelve Months by Current Age, Cape Coast and Mankrong

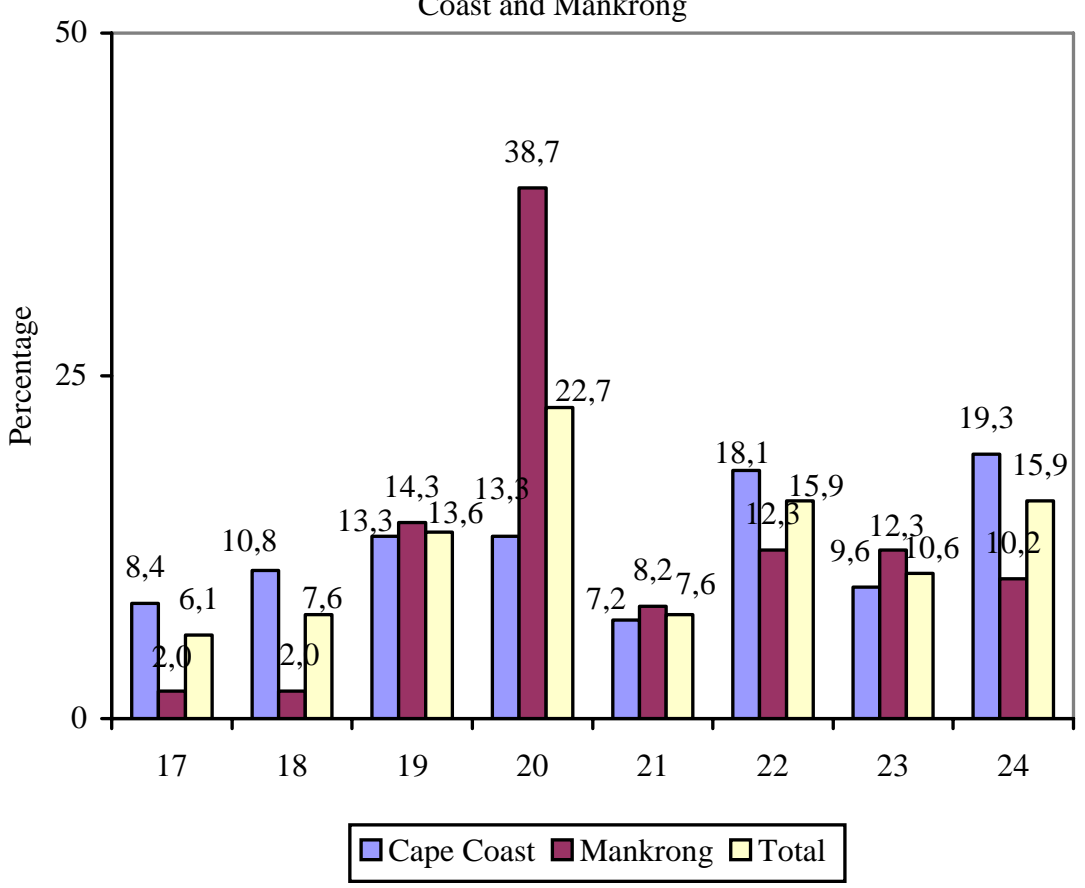

In sum, although the overall pregnancy occurrence is higher in the rural settlement of Mankrong, pregnancy incidence appeared to be much earlier in Cape Coast. This is a problem that should not escape the attention of policy makers although possible age misreporting in respect of first pregnancies cannot be ruled out.

\section{Age At First Birth}

The timing of first births is crucial in determining possible fertility levels. The analysis of first births was based on the premise that when people give birth quite early in life there is a high tendency for them to have subsequent births in quick succession especially when the first births are not the result of marriage.

The results of the analysis (Table 9) pointed to the same mean age at first birth in Mankrong (19.4 years) and Cape Coast (19.5 years). This is quite unexpected because, with a much lower mean age at first pregnancy in Cape Coast, it should have followed that mean age at first births should accordingly be lower in Cape Coast than in Mankrong. The inconsistency could however, occur considering that not all the reported pregnancies might end in a birth those inconsistencies are likely to occur. This is because some of the first births 
could actually be the products of second and third pregnancies rather than first pregnancies in view of possible pregnancy losses.

Table 9. Mean Age at First Birth Among Female Adolescents and the Youth by Current Age, Cape Coast and Mankrong

\begin{tabular}{|l|l|l|l|l|l|l|l|l|l|}
\hline \multirow{2}{*}{ Study Area } & \multicolumn{7}{|c|}{ Current Age } & \multirow{2}{*}{ Total } \\
\cline { 2 - 10 } & $\mathbf{1 7}$ & $\mathbf{1 8}$ & $\mathbf{1 9}$ & $\mathbf{2 0}$ & $\mathbf{2 1}$ & $\mathbf{2 2}$ & $\mathbf{2 3}$ & $\mathbf{2 4}$ & \\
\hline Cape Coast & $16.0^{*}$ & 17.1 & 18.0 & 18.2 & 18.8 & 20.4 & 19.4 & 21.1 & 19.5 \\
Mankrong & $17.0^{*}$ & $16.0^{*}$ & 18.1 & 18.8 & 19.3 & 20.3 & 20.9 & 20.2 & 19.4 \\
Total & $16.3^{*}$ & 17.0 & 18.0 & 18.5 & 19.1 & 20.4 & 20.1 & 20.9 & 19.5 \\
& & & & & & & & & \\
\hline
\end{tabular}

Notes: *Less than 5 cases involved.

It is also noted that $22.5 \%$ of the adolescents in Mankrong had had a birth in comparison with $7.5 \%$ in Cape Coast. Among those who had ever had a birth in Cape Coast, $18.6 \%$ were aged less than 20 years, the remaining $81.4 \%$ falling within $20-24$ years. In contrast, it was $13.7 \%$ for those aged less than 20 years in Mankrong and $86.3 \%$ among those who were more than 20 years. This is consistent with the earlier observation of a comparatively higher pregnancy incidence in Cape Coast than in Mankrong.

There was a general observation that mean age at first birth increases with higher age of the adolescent except at age 23 years for Cape Coast and 24 years for Mankrong where there appears to be non-conformity to the overall observation (Table 9). This suggests possible decline in the age at first birth with time, a situation which does not present healthy signals to the development of the adolescents although on the whole the proportion that reporting ever having a birth is quite small.

\section{Adolescent Fertility and Pregnancy Wastage}

The study investigated into actual childbearing performance among the adolescents within the last 12 months before the survey as well as number of children ever born. It was found that only $3.6 \%$ of all the adolescents in Cape Coast had given birth within the 12 months preceding the survey compared to $12.3 \%$ in Mankrong (Table 10). There were also two persons in Cape Coast who reportedly were pregnant at the time of the survey but were not included in the table. The table shows a consistently higher childbearing performance in Mankrong than in Cape Coast. It, on the other hand, supports the earlier observation of a higher proportion of childbearing contributed by adolescents of less than 20 years in Cape Coast (18.6\%) than their counterparts in Mankrong (13.7\%). In each study area, childbearing is obviously higher among older adolescents 20-24 years compared to their younger counterparts who are less than 20 years. This is to be expected because a higher proportion of women of 20-24 years were found to be married relative to adolescents of 15-19 years. 
Table 10. Percent of Female Adolescents Having Births in the Past Twelve Months Before the Survey by Current Age, Cape Coast and Mankrong

\begin{tabular}{|l|c|c|c|c|c|c|c|c|c|c|}
\hline \multirow{2}{*}{$\begin{array}{l}\text { Study } \\
\text { Area }\end{array}$} & \multicolumn{7}{|c|}{ Current Age } & \multicolumn{2}{|c|}{ Total } \\
\cline { 2 - 10 } & $\mathbf{1 7}$ & $\mathbf{1 8}$ & $\mathbf{1 9}$ & $\mathbf{2 0}$ & $\mathbf{2 1}$ & $\mathbf{2 2}$ & $\mathbf{2 3}$ & $\mathbf{2 4}$ & $\mathbf{~ N}$ & $\mathbf{\%}$ \\
\hline Cape Coast & 1.8 & 9.3 & 11.1 & 16.7 & 5.5 & 22.2 & 9.3 & 24.1 & 54 & 100.0 \\
Mankrong & 2.5 & - & 15.0 & 42.5 & 5.0 & 15.0 & 10.0 & 10.0 & 40 & 100.0 \\
Total & 2.1 & 5.3 & 12.8 & 27.7 & 5.3 & 19.1 & 9.6 & 18.1 & 94 & 100.0 \\
& & & & & & & & & & \\
\hline
\end{tabular}

Note: The percentage is of the total number of respondents in Cape Coast and Mankrong respectively.

It was also found (Table 11) that more than two-thirds of adolescents who had ever had a birth at the time of the survey had had only one birth with a slightly higher figure in Mankrong (75.4\%) than in Cape Coast (72.8\%).

Table 11. Percent of Adolescents by Number of Children Ever Born and Current Age, Cape Coast and Mankrong

\begin{tabular}{|c|c|c|c|c|c|c|}
\hline \multirow{2}{*}{$\begin{array}{c}\text { Current } \\
\text { Age }\end{array}$} & \multicolumn{6}{|c|}{ Number of Children Ever Born } \\
\cline { 2 - 7 } & \multicolumn{7}{|c|}{ Cape Coast } & \multicolumn{3}{c|}{ Mankrong } \\
\cline { 2 - 7 } & $\mathbf{1}$ & $\mathbf{2}$ & $\mathbf{3 +}$ & $\mathbf{1}$ & $\mathbf{2}$ & $\mathbf{3 +}$ \\
\hline 17 & 2.4 & - & - & 1.8 & - & - \\
18 & 7.2 & 4.0 & - & 1.8 & - & - \\
19 & 12.1 & 4.0 & 16.7 & 12.7 & 8.3 & - \\
20 & 18.1 & 16.0 & 16.7 & 36.5 & 33.3 & 16.7 \\
21 & 7.2 & 8.0 & - & 14.5 & 8.3 & - \\
22 & 15.7 & 20.0 & 16.7 & 14.5 & - & 33.3 \\
23 & 8.4 & 16.0 & 33.2 & 12.7 & 16.8 & 16.7 \\
24 & 28.9 & 32.0 & 16.7 & 5.5 & 33.3 & 33.3 \\
Total \% & 72.8 & 21.9 & 5.3 & 75.4 & 16.4 & 8.2 \\
$\mathrm{~N}$ & 83 & 25 & 6 & 55 & 12 & 6 \\
& & & & & & \\
& & & & & & \\
& & & & & & \\
\hline
\end{tabular}


On the other hand, a higher proportion (21.9\%) of the respondents in Cape Coast had had two births compared to $16.4 \%$ in Mankrong. In contrast, a slightly higher proportion of the respondents had had up to three or more births in Mankrong (8.2\%) as against Cape Coast (5.3\%). It is significant to observe that only four of the respondents who were less than 20 years had had two or more births, three in Cape Coast and one in Mankrong. Thus, for each category of births, the highest proportions were between 20 and 24 years whether in Mankrong or Cape Coast.

The results of the analysis on pregnancy wastage due to induced abortion showed that $4.9 \%$ or 74 adolescents from Cape Coast reported to have ever had an abortion (Figure 3). However, this number formed $42.0 \%$ of the adolescents in Cape Coast who had ever been pregnant. Obviously, this is on the high side suggesting that pregnancy wastage as a result of induced abortion is quite high among adolescents who ever became pregnant.

In contrast, 12 adolescents from Mankrong made up of only 3.7\% of all the respondents interviewed in Mankrong and 14.5\% of those who had ever been pregnant in the village reported to have had an abortion. This shows a higher abortion rate in Cape Coast compared to Mankrong. This may be due to the availability of more health facilities and personnel in Cape Coast (an urban area) that facilitate the provision of relatively smooth abortion services in contrast to Mankrong (a rural area). It could also be the result of differences in accuracy of reporting which may be better in Cape Coast than in Mankrong. It is also possible that the idea of menstruation regulation using local herbs is more likely in rural Mankrong than Metropolitan Cape Coast.

Figure 3. Percent of Female Adolescents Ever Terminating a

Pregnancy by Current Age, Cape Coast and Mankrong

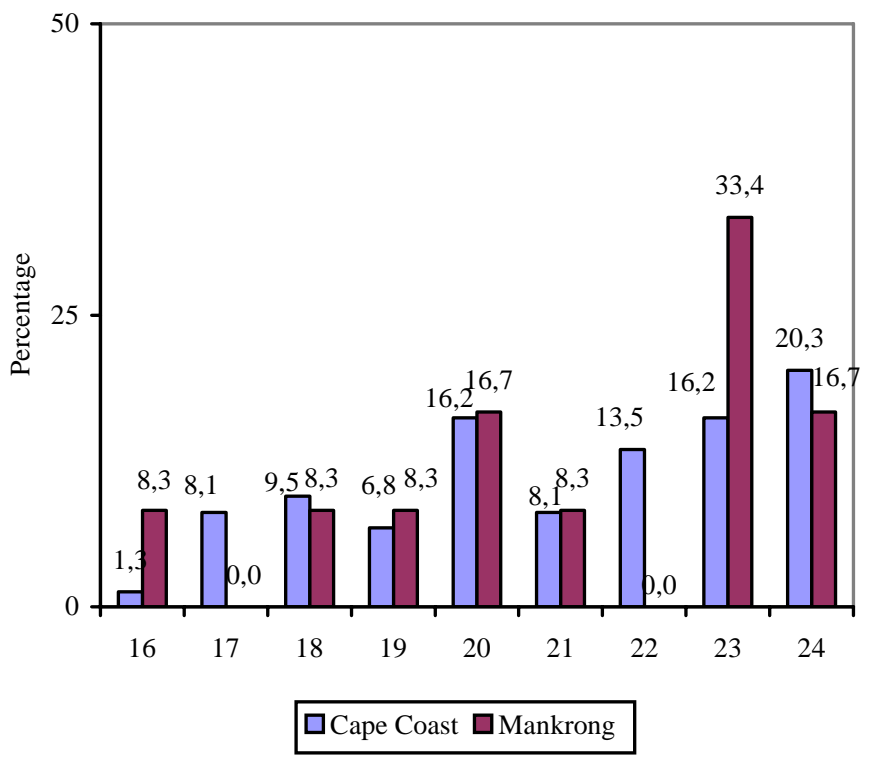


At the same time, reported cases of abortion whether in Cape Coast or Mankrong were among adolescents of at least 16 years old. From Figure 3, a relatively higher proportion of reported abortion occurred to persons aged between 20 to 24 years than among those less than 20 years.

It was also observed in Table 12 that some of the adolescents had had more than one abortion. In the same table, the observation is that for Cape Coast, $67.6 \%$ of adolescents ever becoming pregnant who had ever had an abortion had had it once while $23 \%$ and $9.4 \%$ respectively had had it two and three or more times. On the other hand, only one adolescent of 24 years in Mankrong had had abortion two times, all the other 11 ever pregnant adolescents, $(91.7 \%)$ had had abortion once. It is also important to draw attention to the fact that one person each at 16, 17, 18 and 19 years reported to have had abortion two times.

On the other hand, it was found that the proportion of adolescents less than 20 years in Cape Coast that had one abortion only was higher $(73.7 \%)$ than their counterparts aged $20-24$ years $(65.5 \%)$. This suggests that relatively higher proportions of the youth aged 20-24 years have had two times or more abortions than their younger counterparts of less than 20 years. 
However, due to the stigma that goes with abortion in Ghana, only few people would ordinarily report accurately the number of abortions they have ever had. A matrix of the number of pregnancies and births ever had among the adolescents in the two study areas was constructed (Tables 12 and 13). From Table 12, a total of 278 pregnancies were reported to have occurred among all the adolescents in Cape Coast out of which 151 births (54.3\%) occurred. Thus, 127 (45.7\%) might have ended in pregnancy wastage. This suggests that the $42.0 \%$ reported abortion observed earlier may have been on the low side. It is therefore possible that more adolescents might have carried out abortion but failed to report as such.

Table 12. Percent Distribution of Female Adolescents (15-24 Years) by Number of Births and Pregnancies Ever Had, Cape Coast

\begin{tabular}{c|c|c|c|c|c|c|c|c|c|}
\hline \multirow{2}{*}{$\begin{array}{c}\text { Number } \\
\text { of Births }\end{array}$} & \multicolumn{8}{|c|}{ Number of Pregnancies } \\
\cline { 2 - 9 } & $\mathbf{0}$ & $\mathbf{1}$ & $\mathbf{2}$ & $\mathbf{3}$ & $\mathbf{4}$ & $\mathbf{5}$ & $\mathbf{6}$ & Total \\
\hline 0 & 100.0 & 41.9 & 26.0 & 20.0 & 33.3 & - & 100.0 & 92.4 \\
& $(1,327)$ & $(44)$ & $(13)$ & $(3)$ & $(1)$ & & $(1)$ & $(1,389)$ \\
1 & - & 58.1 & 34.0 & 20.0 & 33.3 & 50.0 & - & 5.5 \\
& & $(61)$ & $(17)$ & $(3)$ & $(1)$ & $(1)$ & & $(83)$ \\
2 & - & - & 40.0 & 20.3 & 33.3 & 50.0 & - & 1.7 \\
& & - & $(20)$ & $(3)$ & $(1)$ & $(1)$ & & $(25)$ \\
3 & - & - & 40.0 & - & - & - & 0.4 \\
& & & $(6)$ & & & & $(6)$ \\
Total & 88.3 & 7.0 & 3.3 & 1.0 & 0.2 & 0.1 & 0.1 & 1,503 \\
& $(1,327)$ & $(105)$ & $(50)$ & $(15)$ & $(3)$ & $(2)$ & $(1)$ & $(100.0)$ \\
& & & & & & & & \\
&
\end{tabular}

Similarly, in Table 13, 120 pregnancies were reported to have occurred among the female adolescents in Mankrong. However, 98 (81.7\%) of the total number of pregnancies ended in births and hence, by implication, the remaining 22 , constituting $18.3 \%$ of the number of pregnancies could have resulted in pregnancy wastages including abortion. In reality therefore, about $27 \%$ of the reported pregnancies might have been aborted compared to a low reported abortion rate of $14.5 \%$ among adolescents who had ever become pregnant. 
Table 13. Percent of Female Adolescents (15-24 Years) by Number of Births and Pregnancies Ever Had, Mankrong

\begin{tabular}{|c|c|c|c|c|c|c|}
\hline \multirow{2}{*}{$\begin{array}{c}\text { Number } \\
\text { of Births }\end{array}$} & $\mathbf{0}$ & $\mathbf{1}$ & $\mathbf{2}$ & $\mathbf{3}$ & $\mathbf{4}$ & Total \\
\cline { 2 - 6 } & 100.0 & 16.1 & 5.6 & - & - & 77.5 \\
& $(242)$ & $(9)$ & $(1)$ & & & $(252)$ \\
& - & 83.9 & 44.4 & - & - & 16.9 \\
1 & & $(47)$ & $(8)$ & & & $(55)$ \\
& - & - & 50.9 & 37.5 & - & 3.7 \\
2 & & & $(9)$ & $(3)$ & & $(12)$ \\
3 & - & - & - & 62.5 & - & 1.6 \\
& & & & $(5)$ & & $(5)$ \\
4 & - & - & - & - & 100.0 & 0.3 \\
& & & & & $(1)$ & $(1)$ \\
Total & 74.5 & 17.2 & 5.5 & 2.5 & 0.3 & 100.0 \\
& $(242)$ & $(56)$ & $(18)$ & $(8)$ & $(1)$ & $(325)$ \\
\hline
\end{tabular}

Notes: Total number of pregnancies $=120$ made up of 98 births $(81.7 \%)$ and 22 wastages $(18.3 \%)$. Brackets represent number of cases

On the reasons for terminating the pregnancies at the time they did. Three major considerations emerged from the analysis. In the case of adolescents in Cape Coast, the major reason was that they were not ready at the time of the pregnancy to have a child (39.2\%). The second major reason was the desire to complete their education (28.4\%). In contrast, among adolescents in Mankrong the most cited reason for embarking on an abortion was that the male partner was either not working or had proved to be financially incapable of taking care of both mother and baby (41.6\%). The reason of wanting to complete one's education was the second (most cited reason given by one in four of those ever undertaking an abortion in that community). It is worth noting that at least, one out of every four adolescents that became pregnant had the desire to complete education before entering into childbearing.

With respect to the place or person from whom the abortion service was procured, it was observed that trained medical personnel carried out almost three out of every four abortions in Cape Coast compared to a little more than half the number in Mankrong. Although it is the view of this study that abortion should not be resorted to except in situations where the pregnancy is the result of incest, rape or where the health of the mother is at a serious risk, whenever it becomes necessary to undertake an abortion, then it has to be done at the right place and by medically trained persons to avoid or reduce complications or deaths

In the case of Mankrong, one in every three cases of abortion was reported to have been assisted by a friend who obviously may not be a qualified medical professional. Some were also reported to have been by self-inducement $(13.5 \%$ 
in Cape Coast and 8.3\% in Mankrong). Two adolescents also indicated to have had an abortion service from a traditional healer in Cape Coast, suggesting possible disastrous consequences on the reproductive and physical health of the persons procuring the abortion.

\section{Incidence of Pregnancy and School Attendance}

The most negative impact of an adolescent's pregnancy on her development is felt when it finally leads her dropping out of school. For example, Ajayi et. al. (1991) report that early untimely pregnancy results in expulsion from school at the rate of $10 \%$ annually in Kenya. In the light of this, the study asked the adolescent females that had ever become pregnant whether their first pregnancies occurred when they were in school and what happened thereafter.

The distribution of incidence of pregnancy and school attendance is presented in Tables 14 and 15 using current age and age at first pregnancy respectively. From the analysis based on current age, no uniform pattern was observed except that a relatively higher proportion of the pregnancies that occurred while the adolescents were in school was among adolescents of less than 20 years compared to those of 20-24 years. Again, in Table 15, it is noted that in both Cape Coast and Mankrong, among those who reported to have been pregnant while in school, relatively higher proportions were at younger ages at first pregnancy (i.e., less than 20 years) compared to older ages (i.e., 2024 years). As it is shown, in Cape Coast, about $28 \%$ of the pregnancies occurred in school among adolescents of less than 20 years compared to $16.0 \%$ among those of 20-24 years. The corresponding figures for Mankrong are about 17.0\% and $4.0 \%$ respectively. This is to be expected since it is usually at younger ages that most of the women are likely to be in school especially in the urban areas.

Table 14. Percent of Female Adolescents Ever Becoming Pregnant by Curren Age and Whether First Pregnancy Took Place While in School, Cape Coast and Mankrong

\begin{tabular}{|c|c|c|c|c|c|c|}
\hline \multirow{2}{*}{ Age } & \multicolumn{3}{|c|}{ Cape Coast } & \multicolumn{3}{c|}{ Mankrong } \\
\cline { 2 - 7 } & Yes & No & N & Yes & No & N \\
\hline $16-19$ & 39.5 & 60.5 & 43 & 18.2 & 81.8 & 13 \\
$20-24$ & 18.9 & 81.1 & 132 & 12.9 & 87.1 & 70 \\
Total \% & 24.0 & 76.0 & 175 & 13.3 & 86.7 & 83 \\
\hline
\end{tabular}

Note: One person of age 21 years did not state whether her first pregnancy occurred while she was in school or not and is not included in the table. 
Table 15. Percent of Female Adolescents Ever becoming Pregnant by Age at First Pregnancy and Whether First Pregnancy Took Place While in School, Cape Coast and Mankrong

\begin{tabular}{|c|c|c|c|c|c|c|}
\hline Age at First & \multicolumn{3}{|c|}{ Cape Coast } & \multicolumn{3}{c|}{ Mankrong } \\
\cline { 2 - 7 } Pregnancy & Yes & No & N & Yes & No & N \\
\hline$<20$ & 27.7 & 72.3 & 119 & 16.7 & 83.3 & 60 \\
$20-24$ & 16.1 & 83.9 & 56 & 4.3 & 95.7 & 23 \\
Total \% & 24.0 & 76.0 & 133 & 13.3 & 86.7 & 72 \\
\hline
\end{tabular}

Notes: One person did not state her age at first pregnancy and is not included in the table.

\section{Analysis of the Relationships}

Table 16 presents the results of multiple regression analysis in respect of possible factors that could explain the age at first sexual intercourse among adolescent females. It is observed that many of the variables used are statistically not significant for reasons of small sample size, considering that just $37 \%$ of the respondents had ever had a sexual encounter. When this is further broken down to variable categories, it reduces the statistical significance of the analysis, thus contributing to the large standard errors shown in the table. In spite of this limitation, the results are quite useful as they provide some plausible guide to understanding the relationships, interpretation should done with caution.

Table 16. Results of Multiple Regression Analysis on Age at First Sexual Intercourse by Selected Background Variables

\begin{tabular}{|l|c|c|c|c|}
\hline \multicolumn{1}{|c|}{ Variable } & B & S.E & Beta & Sig. F \\
\hline Age & .4227 & .0286 & .5366 & .0000 \\
\hline Household Living Arrangements & \multicolumn{5}{l|}{} \\
\hline Both Parents & RC & & & \\
Husband & -.9313 & .3171 & -.1176 & .0034 \\
Father Alone & .2128 & .2728 & .0272 & .4356 \\
Mother Alone & .2123 & .1907 & .0435 & .2659 \\
Alone & -1.252 & .6939 & -.0601 & .0718 \\
Other Relation & -.1401 & .1700 & -.0336 & .4068 \\
Unrelated & .3438 & .2785 & .0439 & .2175 \\
Friends & -.1553 & .6821 & .0075 & .8199 \\
\hline Education & \multicolumn{5}{|l}{} \\
\hline No Education & RC & & & \\
Primary & -.2917 & .2534 & -.0524 & .6691 \\
Middle/JSS & -.1033 & .2168 & -.0264 & .6339 \\
Secondary/SSS & .1089 & .2548 & .0236 & .6691 \\
Post Secondary/Higher & .2521 & .3489 & .0312 & .4703 \\
\hline
\end{tabular}




\begin{tabular}{|c|c|c|c|c|}
\hline \multicolumn{5}{|c|}{ Contraceptive Use at First Sex } \\
\hline $\begin{array}{l}\text { Yes } \\
\text { No }\end{array}$ & $\begin{array}{c}\mathrm{RC} \\
-.3830\end{array}$ & .1498 & -.0974 & .0108 \\
\hline \multicolumn{5}{|c|}{ Knowledge of Ovulatory Cycle } \\
\hline $\begin{array}{l}\text { Yes } \\
\text { No }\end{array}$ & $\begin{array}{l}\mathrm{RC} \\
.2121\end{array}$ & .1354 & .0533 & .1179 \\
\hline \multicolumn{5}{|c|}{ Knowledge of Contraception } \\
\hline $\begin{array}{l}\text { Yes } \\
\text { No }\end{array}$ & $\begin{array}{c}\mathrm{RC} \\
.0522\end{array}$ & .2227 & .0093 & .8149 \\
\hline \multicolumn{5}{|l|}{ Marital Status } \\
\hline $\begin{array}{l}\text { Never Married } \\
\text { Currently Married } \\
\text { Previously Married }\end{array}$ & $\begin{array}{c}\mathrm{RC} \\
-.1011 \\
-.5221\end{array}$ & $\begin{array}{l}.1975 \\
.5084\end{array}$ & $\begin{array}{l}-.0207 \\
-.0338\end{array}$ & $\begin{array}{l}.6086 \\
.3049\end{array}$ \\
\hline \multicolumn{5}{|l|}{ Reasons for First Sex } \\
\hline $\begin{array}{l}\text { Had the Urge } \\
\text { Mutual Consent } \\
\text { Was of Age } \\
\text { Curiosity } \\
\text { Financial Reasons } \\
\text { Peer Pressure } \\
\text { Seduced } \\
\text { Don't Know }\end{array}$ & $\begin{array}{c}\mathrm{RC} \\
-.3189 \\
1.0943 \\
-.3040 \\
-.4957 \\
.1767 \\
-.4107 \\
.2461 \\
\end{array}$ & $\begin{array}{l}.2310 \\
.3713 \\
.2320 \\
.2325 \\
.2245 \\
.2103 \\
.3048\end{array}$ & $\begin{array}{r}-.0475 \\
.0994 \\
-.0449 \\
.0727 \\
.0272 \\
-.0683 \\
-.0268\end{array}$ & $\begin{array}{l}.1679 \\
.0033 \\
.1906 \\
.0334 \\
.4315 \\
.0513 \\
.4197\end{array}$ \\
\hline Constant & 8.7152 & .6162 & - & .0000 \\
\hline $\begin{array}{l}\text { R Squared }=.3298 \\
\text { Adjusted } \mathrm{R}=.3052 \\
\text { Signif. } F=.0000\end{array}$ & rence & & & \\
\hline
\end{tabular}

Overall, the variables included in the analysis explained just about onethird $(31 \%)$ of the variation in the age at first sexual intercourse among the young women under discussion. Although this is quite low, it is understandable in view of the limitations already stated which did not make the inclusion of other variables which could offer some additional explanation.

At the individual variable level, some observations are worth highlighting in spite of the lack of statistical significance of many of the variables. The first relevant observation is the effect of current age of the adolescent, which suggests that a unit increase in the current age of the female adolescent tends to increase the age at first sexual activity by 0.42 units. In other words, it shows that there has been a decline in the age at first sex over the years. This means that young women are entering into sexual practices earlier in recent times than their older counterparts. This was found to be statistically significant at $100 \%$ level of confidence. 
With reference to the views expressed by both adults and adolescents in the focus group discussions, the observed declining trend in age at first sexual activity is not unexpected. While most of the adults condemned the involvement of unmarried adolescents in sexual practices, many of the adolescents, although generally did not support sexual practice by adolescents, nonetheless justified it on the grounds that parents are unable to provide them with their basic needs. It is therefore abundantly clear that if parents would live up to their responsibility towards their children and wards, sexual activity may not be a consideration among many adolescents as was survival strategy.

Of all the categories of living arrangements shown in Table 16, the results are statistically significant among adolescents who were staying with their husbands at $99.7 \%$ level of confidence and at $92.8 \%$ level of confidence among adolescents who were staying alone. The relevant lessons to be learnt from this are first, adolescents who live all by themselves tend to have first sexual activity the earliest i.e., 1.25 years earlier than their counterparts who live with both of their parents. They are followed by adolescents who stay with their husbands who have 0.93 years earlier entry into sexual activity than their colleagues who live with both parents.

At the same time, females who live with their friends also have 0.15 years of earlier entry into sexual activity than their counterparts staying with both parents although the result is not statistically significant. There is no significant difference between adolescents who live with their fathers alone and those who are with their mothers only. What is not usual is that these two categories of adolescents appear to enter into first sexual activity 0.21 years later than those with both parents.

One would have thought that one of the main factors that would predispose a young girl to stay with only one of the parents is the incidence of broken homes which, in itself has the tendency to lead young children into anomic behaviours. The reason is that often the care for children in broken homes is not adequate especially when the children depend on the low income of one of the parents. This, however, cannot be overstretched since the results are not statistically significant.

In terms of education, although none of the categories showed statistically significant results, yet a clear direct relationship appears to emerge between level of education and age at first sexual activity. This implies that the pursuit of higher education is likely to increase the age at which females begin sexual activity. The caution here however, is that the timing of the first sexual activity occurred at a point in time when the educational attainment of the woman might not have been the same as the current educational level (i.e., at the time of the survey). 
Another relevant finding, which is also statistically significant at $99 \%$ level of confidence is the relationship between contraceptive use at first sex and age at first sex. As is shown in Table 16, adolescents who do not practice contraception at first sex are likely to have an earlier sexual practice than their counterparts who use any form of contraception at first sexual activity. Here, adolescents who do not practice contraception at first sex tend to reduce their age at first sexual encounter by 0.38 years in comparison with their counterparts who practice contraception at first sex. The suggestion is that late incidence of first sex is associated with contraceptive use among females. This confirms the hypothesis that there is a direct relationship between contraceptive use at first sex and age at first sexual activity among adolescent females. It is therefore important that first sexual activity is delayed to ensure that when it does take place, the sexual act will reduce the risk of the partners to either unwanted pregnancy or STI or both. Incidentally, the results in respect of knowledge of contraception and the ovulatory cycle are to the contrary although statistically not significant.

The reason for one's first sexual practice was included in the multiple regression analysis to find out whether it was important in influencing the timing of the first sexual act. From the results, three reasons namely, a consideration that one was of age to practice sex, financial consideration and the issue of education showed a high level of statistical significance. Among these, financial consideration so far appears to contribute more to reduction in a woman's age at first sexual activity. As shown in Table 16, adolescents, who quoted financial reasons for their first sexual encounter, have almost 0.50 years reduction in their age at first sex compared to their counterparts who reported that their first sexual practice was based on their conviction that they had the urge to do so. This is quite consistent with the views expressed in the focus group discussions all of which suggested the possibility of young females succumbing to a sexual proposal when financial gains are likely to be the reward. Thus, poverty cannot escape blame in any effort at explaining early sexual practices by adolescents in recent times.

\section{Discussion}

One major finding was that of a smaller percentage of adolescents ever having sex after 20 years in the rural areas compared to the urban. This may be due to the observation that in the rural areas, adolescents who attain age 20 years without continuing their education are likely to have entered into sexual activity during their teen ages. Thus, during 20-24 years, a relatively smaller proportion of adolescents may be left yet to initiate sexual intercourse compared to adolescents in urban areas, most of whom may continue their formal education. One could however, not rule out possible misstatement of age at first sex by the adolescents in Mankrong (the rural area). 
Early age at sex exposes adolescents to reproductive health risks. In Zimbabwe, it has been explained that, "stereotyped sexual norms and peer pressure encourage young males to prove their manhood and enhance their social status by having sex" (Kim et al., 2001:11). On the other hand, according to Kim et al., young women are socialized to be submissive and not to discuss sex, thereby leaving them to be unable to refuse sex or insist on condom use. Among those who had ever married, there appears to be a declining age at marriage over the years. It has to be noted however, that a large proportion of the respondents especially the young ones were still not married at the time of the survey. The tendency for them to postpone marriage cannot therefore be in doubt. This is a positive development that should be sustained.

As much as possible women should be educated to be circumspect in yielding to the influence of their friends in their decision to marry since that practice has shown a tendency for young women to marry earlier when the influence is from their friends rather than their parents, other relations or male partners. Peer pressure such as from friends or age mates thus, seems to play a major contributory role in bringing about early marriages among adolescent females in Ghana. The proportion having had two or three pregnancies was slightly higher in Cape Coast (27.4\% and $12.0 \%$ respectively) compared to $21.7 \%$ and $10.8 \%$ respectively in Mankrong. This shows that although, a relatively higher proportion of the respondents in Mankrong had ever become pregnant, the proportion having more than one pregnancy is higher in Cape Coast than in Mankrong. This finding is quite contrary to expectation because in urban areas, although one could be pregnant at an early age, opportunities including easier access to information on contraception relative to rural areas may reduce the number of subsequent pregnancies among adolescents in urban areas compared to those in rural areas.

An inverse relationship between mean age at first pregnancy and the number of times pregnant was observed. This means that the earlier an adolescent becomes pregnant for the first time, the more likely she is to have more subsequent pregnancies. Thus, if first pregnancy is postponed, it is possible that the number of pregnancies that may occur to them in their adolescent ages could be reduced. This finding is to a large extent consistent with a Guatamalan study where there was an observed association between early childbearing and higher completed fertility (Buvinic, 1998).

The general concern of the focus group discussions was that patience need to be exercised with respect to pregnant girls, else some of them would commit suicide or attempt an abortion and in the process may lose their lives. For example, one adult in Cape Coast advised that parents "should be patient with school girls who get pregnant and assist the male partner who is responsible for the pregnancy to take care of her in order not to drag her 
to take her life". There were also suggestions that when parents are patient with the pregnant adolescents, they could be encouraged to go back to school. However, one female adult in Mankrong, citing the case of her own sister, explained that some of them would refuse to go to school, after giving birth notwithstanding how lovingly their parents would handle them.

In support of the position of most of the adults, one female adolescent in Mankrong was of the view that when pregnant girls are not handled with care and love, it could affect their health and that of the babies they give birth to. To her, part of the high infant mortality among adolescents is the result of the negative attitude of some parents towards their daughters when they disappointingly become pregnant. One female adolescent in Cape Coast was, however, of the opinion that the adolescent girl who gets pregnant while in school should be reprimanded to serve as deterrent to her other sisters. This is because, in her view, when they are "pampered" during their period of pregnancy, most of them do not learn any lessons and get pregnant again still without husbands, thereby, bringing more burden to their parents.

From the analysis, it is valid to state that the abortion rate could be higher than was reported by the adolescents. On the other hand, the reported higher abortion rate in Cape Coast compared to Mankrong is again supported by the further analyses of the relationship between number of pregnancies and actual childbearing and their corresponding deductions. The limitation here, however, is that it was not possible to calculate the number of pregnancy wastage due to miscarriage from those that were the result of intentionally induced processes.

Information on abortion among adolescents is difficult to elicit from respondents due to the fact that the 1960 Criminal Code, Act 29 (58-63) makes abortion illegal in Ghana. The exceptions however, are under conditions of rape, incest or maternal health. According to Nabila and Fayorsey (1996), most adolescent females have developed a social network system which tends to keep abortion incidence as secret as possible. From this observation therefore, the reported abortion rates could be an underestimation of what the situation may be on the ground.

The shortfall in the reported cases of abortion compared to the actual is consistent with findings of earlier studies in Ghana as a result of the fact that abortion is illegal in the country in addition to the stigma that goes with it in the Ghanaian society (see Nabila and Fayorsey, 1996). Given the opportunity however, it is clear that many of the adolescents becoming pregnant would avoid the pregnancy in order to complete school. Yet, it appears these adolescents lack both information and services that could save them from first becoming pregnant and hence not to contemplate on an abortion which could have long term and at times irreversible negative impacts on their health.

There are still other persons who feel that abortion is a family planning method. For example, many sexually active adolescents who were 
interviewed in Kumasi and Accra as to why they do not practice contraception, said that they could go for an abortion any time they become pregnant (Kwankye, 1999).

In response to a question as to whether they would agree that a girl who has an unplanned pregnancy should go for an abortion and why they support it, participants in the focus group discussion disagreed with the view that it is advisable to embark on abortion no matter the situation. Many of the reasons that were given in support of their opinions touched on the fear that abortion could lead to complications such as sterility or death to the victim. For example, some of them indicated that an abortion could cause barrenness to the girl in future and indicated that, "some of the victims in the long run blame their mothers (who might have encouraged them to go for the abortion) for bewitching them and being behind their inability to give birth in future". According to them, such a development should be discouraged since it destabilizes whole families and households.

The adolescents were all unanimous in their suggestion that young girls who become pregnant should be encouraged to give birth and thereafter, be assisted to continue their education. To many of them, "any form of abortion is tantamount to murder". However, two adolescents in Cape Coast were of a different opinion. One of them argued that "abortion is good if it is upon the advice of a doctor". To another, "it may be good if there is no hope to care for the child". With respect to the health-related problems of abortion, almost all of them mentioned the possibility of death occurring or becoming sterile. For example, one male adult in Mankrong cited a case in point and argued that there is always a possibility that the future birth performance of an abortion victim would be negatively affected. In the example he cited, "a lady had undertaken an abortion contrary to all advice. Later on, she could not give birth again". Their concern, in this respect, was expressed more in the context of the Ghanaian culture, which makes childlessness more of an abomination than abortion having any health effects on the individual who goes for it. It is therefore important that people are sensitized on the health effects of abortion rather than the cultural underpinnings when future births are curtailed as a result of abortion carried out in the past.

Judging from the views expressed in the focus group discussions, one would have thought that abortion would not be a problem in Ghana but the reality is to the contrary. In this study it has been established that in spite of the small proportion of adolescents who reported to have ever had an abortion, the analysis points to perhaps a higher proportion than was reported. It thus, seems quite clear that when it is a question of abortion, what people believe in and talk about is quite different from what they practice. 
The study also found that out of 42 female adolescents in Cape Coast who became pregnant while in school, 16 of them (38.1\%) dropped out of school compared to nine $(81.8 \%)$ of the 11 female adolescents in Mankrong who became pregnant while attending school. This finding is also consistent with the earlier observation that a relatively higher abortion cases were reported in Cape Coast than in Mankrong. It is possible then that many of the pregnant women who otherwise would have dropped out of school in Cape Coast may have resorted to abortion making it possible for them to continue with their education compared to their counterparts in Mankrong many of whom may have no ready access to safe abortion services. This reasoning is again in line with the report of Ajayi et al. (1991) that although abortion is not approved by adolescents in Kenya, it appears to be used in order to stay in school. The concern is the extent to which young persons would be sensitized to act in accordance with their beliefs in matters pertaining to their reproductive health.

\section{Conclusions and Recommendations}

The study has shown clearly that some positive changes have occurred in reproduction among female adolescents especially comparing the results of this study with those of the GDHS of 1993, 1998 and 2003. Problems still exist however, and therefore a lot will have to be done to completely bring the negative aspects of adolescent reproductive health under control in the country.

Intensive and sustained public educational campaigns should be mounted against induced abortion in Ghana. This should be done by educating adolescents about the short and long-term health implications of criminal abortion on the female. The educational campaign should also disabuse the minds of some adolescents that abortion is a family planning method.

Public education campaigns against HIV/AIDS should include the dangers of abortion as it affects the health of abortion victims. The campaign on condom use should equally emphasize abstinence as the surest way to avoid HIV/AIDS as well as STIs. Perhaps, it is about time the Ministry of Education encouraged the formation of Virgin and Secondary Virgin Clubs in schools and colleges as a way of bringing the dignity and virtues of virginity to the fore as one national objective. Guidelines for the formation of these clubs countrywide should however be carefully discussed and evolved by the Ministry of Education and the Ghana Education Service in collaboration with religious bodies in the country. A reward and incentive system should also be built into the organization of these virgin clubs not only for girls but boys as well.

The National Population Council (NPC) and other population implementation agencies should lobby Parliament to make a legislation that would enjoin all District Assemblies to establish District Youth centres where all young persons could go for recreation and counselling on all 
issues including sexual and reproductive health. This is considered very important in view of the difficulty of parents to effectively counsel their children on sexual issues. The Central Government should direct the District Assemblies to use some percentage of the District Assembly Common Fund to establish these youth counselling centres.

In terms of future research, one limitation of this study was that it did not collect information on the education of the adolescents at first sexual intercourse. Thus, it could not relate very well the effect of education on a person's timing of first sexual activity. Future research should therefore take note of this need and include it in the data collection stage to facilitate such an important analysis. Future research should additionally collect information on adolescents' future aspirations pertaining to education as a proxy which when related to current educational level of the adolescent could offer plausible answers to the relationship between adolescents' education and the timing of their sexual activity. Finally, future research should include male adolescents in the analysis.

\section{REFERENCES}

Adjei, S. \& Ampofo, D.A. 1986. Adolescent Fertility: Social and Medical Problems in Ghana. Paper presented at the National Conference on Population and National Reconstruction, April 7-10, University of Ghana, Vol. 2, (A Population Impact Project Publication).

Adomako-Ampofo. A. 1991. Attitudes and Practices Regarding Pre-Marital Sex among adolescents in Ghana. Institute of African Studies, University of Ghana, Legon.

Agyei, W.K. and Epema, E. 1990. Adolescent Fertility in Kampala, Uganda: Knowledge,

Perceptions and Practice. Biology and Society. Vol. 7. No. 4. December, pp. 203214.

Agyei, W.K.A. \& Hill, R.B. 1997. Sexual Behaviour, Reproductive Health and Contraceptive

Use Among Adolescents and Young Adults in Ghana. A Paper presented at the Research seminar to Disseminate Some of the Findings of the Ghana Adolescent Fertility Survey undertaken by the Department of Community Health, Ghana Medical School and the Institute of Urban Research, Morgan State University.

Ajayi, A.A., Marangu, L.T., Miller, J and Paxman, J.M. 1991. Adolescent Sexuality and Fertility in Kenya: a survey of knowledge, perceptions and practices. Studies in Family Planning, July-August, pp. 205-216.

Ampofo, D. A \& Gyepi-Garbrah, B. 1986. Dimensions of Adolescent Pregnancy in Korle-bu

Teaching Hospital 1983-85. Paper presented at the National Conference on Population and National Reconstruction, University of Ghana, Legon.

Anarfi, J.K. 1997. Vulnerability to Sexually Transmitted Disease: Street Children in Accra. Health Transition Review. Suppl. to Vol. 7, pp. 281-306. 
Ankomah, A. and Ford, N. 1993. Pre-marital Sexual Behaviour and its Implication for HIV

Prevention in Ghana. An Occasional Paper, Institute of Population Studies, University of Exeter, K.K.

Asamoah-Odei, E.J., Antwi, P.M., et al. 1992. AIDS Awareness Among Students of Second

Cycle Institutions in Greater Accra Region. Ghana Medical Journal. Vol. 26.

Buvinic, M. 1998. The Costs of Adolescent Childbearing: Evidence from Chile, Barbados, Guatemala and Mexico, Studies in Family Planning, Vol. 29, No. 2, June, pp. 201-

209.

Ghana Statistical Service. 1994. A Situation Analysis Study of Family Planning Service Delivery Points in Ghana. Ghana Statistical Service, Accra, Ghana.

Ghana Statistical Service (GSS) and Macro International Inc. (MI). 1989. Ghana Demographic and Health Survey 1988. Calverton, Maryland.

1994. Ghana Demographic and Health Survey 1993. Calverton, Maryland.

1999. Ghana Demographic and Health Survey 1998. Calverton, Maryland.

2004. Ghana Demographic and Health Survey 2003. Calverton, Maryland.

Ghana AIDS Commission. 2004. Annual Report 2004. Ghana AIDS Commission,

Accra.

Government of Ghana 1994. National Population Policy (Revised Edition). National Population Council, Accra.

Kim, Y. .M, Kols, A., Nyakauru, R., Marangwanda, C. and Chibatamato, P. 2001. "Promoting Sexual Responsibility among Young People in Zimbabwe".Family Planning Perspectives. No. 1, March, pp. 11-18.

Kwankye, S.O. 1999. "Adolescent Sexuality and Health in Ghana", Bulletin of the Ghana Geographical Association, No. 21, July, pp. 88-94.

Kumekpor, T. 1997. Research on Teenage Motherhood and Children's Rights. Department of Sociology, University of Ghana, Legon.

Mohamud, A.A. 1996. "Adolescent Fertility and Adolescent Reproductive Health", Family Planning, Health and Family Wellbeing, Proceedings of the United Nations Expert Group Meeting on Family Planning, Health and Family Wellbeing, Bangalore, India, 26-30 October, Compiled by the United Nations, New York.

Nabila, J.S \& Fayorsey, C. 1996. Adolescent Fertility and Reproductive Health Behaviour in

Ghana: A Case Study of Accra and Kumasi. FADEP Technical Series No. 7, University of Ghana, Legon.

Peprah, K. 1998. Knowledge and Attitudes towards Reproductive Health: A Case Study of Adolescents in Okponglo, Accra. Unpublished Dissertation, University of Ghana, Legon.

Population Impact Project. 1995. Adolescent Fertility and Reproductive Health in Ghana. Population Impact Project. University of Ghana, Legon. 